\title{
Hydrocarbon Potential of the Upper Permian Chia Zairi Formation in Northwest Iraq
}

\author{
Aboosh H. Al-Hadidy (North Oil Company <dr_aboosh_hadid@yahoo.com>) and Adnan \\ A.M. Aqrawi (Statoil<aamaq@statoil.com>)
}

In Iraq the Upper Permian Chia Zairi Formation, together with the overlying Lower Triassic Mirga Mir Formation, forms the chronostratigraphic equivalent for the Khuff Formation of eastern Arabia and the Dalan and Kangan formations of Iran. The Chia Zairi Formation extends from upper-north Ora outcrops near the Turkish border to southern Iraq (wells West Kifil-1 and Diwan-1), thus covering central and eastern parts of the country. It is absent in the far western deserts at the Jordanian border and some areas near the Syrian border (i.e. Khelsia High region and south of Jabal Sinjar) due either to non-deposition or erosion. Lithologically, the Chia Zairi Formation is composed of both carbonates and siliciclastics, and the carbonate proportion increases northward and eastward. However, the formation is deeply buried in most regions except from the northwestern and potentially southwestern region too, where, based on seismic, it is estimated to be around 3-5 km deep.

This study of the Chia Zari Formation in northwest Iraq used data collected from both outcrops (in Ora region of Kurdistan) and deep wells (Atshan-1, Jabal Kand-1 and Mityaha1). The formation is subdivided into four units: $\mathrm{CH} 1$ to $\mathrm{CH} 4$ units downwards. The upper Darriri Member or CH1 carbonates contain regional MFS P30 and P40, which can be correlated with the Khuff C (and possibly the Khuff B) of Saudi Arabia, the Khuff cycles P30 to P40 of Oman, and the upper Dalan Member of Iran. While the middle Satina Evaporite Member (i.e. CH2 unit of subsurface) may be correlated with the Khuff D anhydrites of Saudi Arabia, the Nar Member of Iran, and the middle Khuff anhydrite of Oman and United Arab Emirates. The lower Zinnar Member (probably $\mathrm{CH} 3$ of subsurface) contains carbonates deposited during the Middle Permian transgression and consists of the regional MFS P20 that can be correlated with the Khuff D Member of Saudi Arabia, the lower Dalan Member of Iran, and the Khuff cycles P17-P27 of Oman. This Khuff equivalent, a thick dolomitic limestone, has the potential to form an important gas reservoir in Iraq, particularly in the northwest region. However, the Chia Zairi appears to be characterized by lower porosities compared to the Khuff in the Gulf region.

The main source rocks for the whole Paleozoic plays in Iraq are the proven Lower Silurian Akkas hot shale, in addition to the potential organic-rich shales of the Ordovician Khabour and the Lower Carboniferous Ora formations. The Chia Zairi Formation also has source rock potential in its lower shaly parts (ca. $20 \mathrm{~m}$ thick). This lower shaly part of the formation may also act as a seal for the underlying older reservoir units. 